\title{
Prevalence of malaria and treatment procurement in three local government areas of Ekiti State, Nigeria
}

\author{
Adewole S. O. ${ }^{1}$, Odeyemi D. F. ${ }^{2}$, Omotosho O. A ${ }^{1}$, Dada A.O. ${ }^{1}$ \\ ${ }^{I}$ Department of Zoology and Environmental Biology, Faculty of Science, Ekiti State University, Ado, Ekiti State \\ ${ }^{2}$ Department of Science Laboratory Technology(Biotechnology option), Faculty of Science, Ekiti State University, Ado, Ekiti State \\ *Corresponding author E-mail: profadewole@gmail.com
}

\begin{abstract}
Malaria remains a major health problem in Nigeria. It accounts for over $60 \%$ outpatient visit and $30 \%$ hospital admission in Nigeria. Ineffective treatment of malaria is also one of the factors responsible for its prevalence. The prevalence of malaria and treatment procurement was studied in Ekiti state, Nigeria. The study was carried out using well-structured questionnaire comprising of three sections A to C, Socio-economic, input and output data; data on method, cost of treatment of malaria and expenditure were obtained. Multistage random sampling technique was adopted. The result obtained showed that males with percentage prevalence of 53\% were more infected than females with $47 \%$. Respondent with symptoms of fever and chills was $48.2 \%$ while $51.8 \%$ complained of headache and pains. $80.3 \% \%$ of the respondents have knowledge of malaria transmission while $19.7 \%$ have no idea. $46.7 \%$ of respondents spent less than 1000 naira for treatment procurement while $53.3 \%$ spent more than 1000naira. However, there was a significant difference $(\mathrm{p}<0.05)$ between males and female's susceptibility to malaria disease. Therefore, as at the time of study, there is prevalence of malaria in the communities despite the knowledge of the respondents on transmission of malaria and treatment procured.
\end{abstract}

Keywords: Malaria; Prevalence; Procurement; Respondents; Treatment.

\section{Introduction}

Malaria remains one of the major causes of morbidity and mortality in sub-Saharan Africa because the environment favours the multiplication and sustenance of the parasite causing the disease [1]. Malaria is the most serious health problem in tropical and subtropical regions of the world that has emerged one of the top three killers among vector borne disease in the world. Malaria, a vector borne disease transmitted by female Anopheles mosquito is an endemic disease in Nigeria. The four known species of Plasmodium that cause human malaria are Plasmodium falciparum, Plasmodium vivax, Plasmodium ovale and Plasmodium malariae and they contribute the majority of a human health problem in malaria endemic regions of the world [2]. Malaria remains the major cause of admission in the health centres especially among children under age of five years and pregnant women. The burden of the disease amount to 300-500 million clinical cases every year worldwide with over $80 \%$ occurring in Africa [3]. It was also reported that an estimate of one million people died from malaria each year with $90 \%$ of the deaths occurring in sub-Saharan Africa while 300,000 deaths from malaria occur in Nigeria every year [4]. Symptoms of malaria include headache, fatigue, abdominal discomfort, fever, chills, muscle /joint ache [5]. Description of the physical and mental effects of malaria according to [6] is fatigue, blurred vision, weakness, and inability to concentrate,all of which can reduce a person's productivity level. Malaria is therefore over diagnosed on the basis of symptoms alone, especially in the endemic areas like Nigeria, if treatment is not delayed and effective, there is full and rapid recovery. However if ineffective treatment is administered or treatment is delayed, the disease can progress to severe malaria especially in children which manifests as cerebral malaria, metabolic acidiosis, severe anaemia, hypoglycaemia and acute renal failure or acute pulmonary oodema. A study on the economic impact of malaria suggests a correlation between malaria and poverty in malaria endemic countries. The disease may be responsible for reducing economic growth by close to $1.3 \%$ in a year. In the developing world, especially Africa, malaria is the disease that has the most widespread impacts on growth and developments [7]. Malaria has the greater impact on African human resources than simple lost earnings. The cost of malaria can be measured in lives lost, in time spent ill with fever and in economic terms. The money spent on preventing and treating malaria, the indirect costs of lost wages, time away from school and time spent with sick loved ones in the hospital add up at the personal level [8]. Although difficult to express in monetary terms, another indirect cost of malaria is the human pain and suffering caused by the disease. Malaria also hampers children schooling and social development.

A study of the knowledge and preventive strategies of malaria among migrant farmers in Ado Ekiti, Ekiti state showed that 92\% of the study population have the knowledge about the causes of malaria disease, $86 \%$ knew that malaria can be prevented [1]. However, the knowledge as well as preventive strategies of malaria did not translate to improvement in the practice through preventive measures of malaria [5].

Globally, the impact of malaria is staggering regardless of how it is measured. Biomedically, the burden of a disease is a function of many things, and various public health disciplines defined it differently. Epidemiologists refer to burden in terms of morbidity and mortality while economists refer to a qualification of the costs (direct and indirect) and effects at the level of productivity, national growth and development [9]. Therefore, the objective of this study is to determine the prevalence of malaria and its preventive 
strategies among farmers in the study area and possibly the economic loss due to malaria infections in Ekiti State.

\section{Methods}

\subsection{Study area}

The study was carried out in Ekiti State, which is situated entirely within tropics. It is located between longitude $7^{0} 5-8^{0} 5$ north of the equator and Latitude $7^{0} 5-8^{0} 5$ north of the equator. It lies south of Kwara and Kogi State as well as east of Osun state. The state is mainly an upland zone rising above 250 metres above the sea level Farming activities predominates in the area, and the common crops include cocoa, rice, yam, maize, etc.

\subsection{Data collection}

The data were collected through the use of well-structured questionnaire comprising of three sections A-C. Socio-economic variables and input and output data were obtained. Also Data on method and cost of treatment of malaria were collected.

\subsection{Sampling technique}

The selection of Ekiti state was done based on: the share of the state in national rice cropped area- 268,88 thousand hectares; the share of rice in the state food cropped area- 570,11 thousand tone with another farm produce; the type of dominant rice ecologiesirrigated and lowland[10].

Multistage random sampling technique was adopted. The firs stage involved selection of Ekiti State. The second stage entailed the selection of three local governments, and the third stage is selection of five rural settlements in each local government selected as follows:

Ado Local Government- Irasa settlement, Ajebamidele settlement Ago Aduloju Settlement, Aba Igbira poly annex settlement, Aba Ilora settlement.

Ise -Orun Local Government- Ogbese, Afolu, Obada, Ajegunle, Kajola Settlements

Emure Local Government- Eporo, Upaso,UbejiOwode, UbejiShittu, Ugbo Ode Settlements

Twenty two households were selected from each settlement. The total questionnaires used were 330 .

\subsection{Data analysis}

The data obtained from the study was analysed using both descrip tive and inferential statistics.

\section{Results}

Table 1 showed the number of respondents in each local government and their malaria prevalence. Males $(53.0 \%)$ were more infected than females $(35.8 \%)$. There was a significant difference $(p<0.05)$ between males and female's susceptibility for the disease.

Table 1: Respondents in Each Local Government and the Prevalence of Malaria

\begin{tabular}{llll} 
Location & $\begin{array}{l}\text { Number Ex- } \\
\text { amined }\end{array}$ & $\begin{array}{l}\text { Numbers of Male } \\
\text { infected }\end{array}$ & $\begin{array}{l}\text { Numbers of Fe- } \\
\text { male Infected }\end{array}$ \\
\hline Ado L.G & 110 & 66 & 37 \\
Ise/Orun & 110 & 61 & 41 \\
L.G & 110 & 48 & 40 \\
Emure L.G & 330 & 175 & 118 \\
$\begin{array}{l}\text { Total } \\
\text { Percentage }\end{array}$ & & $53.0 \%$ & $35.8 \%$ \\
\hline
\end{tabular}

Table 2 showed the symptoms experienced by the respondents $42.7 \%$ of the respondents complained of fever and chills while those that complain of headache, pains and others were $46.1 \%$.
There was a significant difference $(\mathrm{p}<0.05)$ between these two groups.

Table 2: Complications Caused by Malaria

\begin{tabular}{lll} 
& Table 2: Complications Caused by Malaria \\
\hline Location & $\begin{array}{l}\text { Total number of people } \\
\text { that complained of fever } \\
\text { and chills }\end{array}$ & $\begin{array}{l}\text { Total number ofpeople that } \\
\text { complained of headache, } \\
\text { pains and others }\end{array}$ \\
\hline Ado L.G & 54 & 48 \\
Ise/Orun & 41 & 62 \\
L.G & 46 & 42 \\
Emure L.G & 46 & 152 \\
Total & 141 & $46.1 \%$ \\
Percentage & $42.7 \%$ &
\end{tabular}

Table 3 showed that a larger percentage $80.3 \%$ of the respondents have the knowledge of how malaria infection is being transmitted while $19.7 \%$ of the people have no idea of what causes the infection.

Table 3: Indigenous Knowledge of the Causes of Malaria among the People in the Study Area

\begin{tabular}{ll}
\hline Categories & Percentage of people in these Category \\
\hline Mosquito bite & $80.3 \%$ \\
Wicked people, white & ------ \\
Good & ------- \\
No idea & $19.7 \%$ \\
\hline
\end{tabular}

Table 4 showed that $41.5 \%$ of the respondents in the study area spent less than 1000 naira for treatment procurement for malaria while $47.2 \%$ spent more than 1000 naira for the treatment of malaria. However, there was no significant difference ( $p>0.05)$ between respondents treatments procurements for malaria.

Table 4: Treatment Procurement for Malaria

\begin{tabular}{lll}
\hline Location & $<1000$ Naira & $>1000$ Naira \\
\hline Ado L.G & 48 & 54 \\
Ise/Orun L.G & 47 & 41 \\
Emure L.G & 42 & 61 \\
Total & $137(41.5 \%)$ & $156(47.2 \%)$ \\
\hline
\end{tabular}

Table 5 showed that $71.8 \%$ of the respondents in the study areas infected by malaria infection are twenty years above while $17.0 \%$ of the participants are below twenty years of age.

There was a significant difference $(p<0.05)$ between males and females susceptibility to malaria disease. Also there was a significant difference $(p<0.05)$ between people that complained of fever/chills and headache/pains of malaria. There was no significant difference $(p>0.05)$ between respondents treatment procurement for malaria.

Table 5: Prevalence of Malaria in Relations to Age Cohorts

\begin{tabular}{lll}
\hline Location & $>20$ years & $<20$ years \\
\hline Ado L.G & 82 & 20 \\
Ise-Orun L.G & 80 & 23 \\
Emure L.G & 75 & 13 \\
Total & $237(71.8 \%)$ & $56(17.0 \%)$ \\
\hline
\end{tabular}

\section{Discussion}

The result shown on table 5 showed that a larger percentage of the farmers are aware of the cause of malaria, which is in accordance with the result of [11] [1]. The prevalence of malaria which is significantly higher $(p>0.05)$ in males than females showed the magnitude of economic loss expected in the community since males are more involved with farming activities than females in correlation with the result of [12]; Furthermore, males are more infected than females because they are involved in family activities, hence prone to malaria disease [13]. On the method of malaria preventive strategies the knowledge of the respondents were poor, which give rise to higher infections and higher treatment procurements. The treatment procurement for malaria showed that out of $88.7 \%$ of respondents, $47.2 \%$ spent more than 1000 for treatment procurement. The heavy cost of burden imposed by 
malaria on household has potentially significant economic consequences as it interferes with the family ability to save and invest in both human and physical capital. Physical capital has proven to be the engine of growth in the rapid growth economics and with the prevalence of malaria in males, there is bound to be the loss in economy. The direct cost of prevention and treatment until the disease ate into the disposable incomes of the poor families so also is the loss in productivity. The non-significant difference in the knowledge of malaria and preventive strategies denotes that majority of the respondents had knowledge of the preventive strategies but however did not commensurate with the prevalence of malaria which supports the claims of [5].

\section{Conclusion and Recommendation}

Based on the findings of this study, the result showed that there is prevalence of malaria in the communities studied, thus can have impact on their economic activities from the fact that males are more susceptible to the disease than females and males are more involved in farming activities than females. Also the treatment procured is not very effective in combating the disease. It is however recommended that the government should promote efforts that will improve the knowledge of the migrant farmers on malaria and its preventive strategies, also ensure all available preventive strategies should be implemented to totally eradicate means of survival of Plasmodium species.

\section{References}

[1] J.A Adegun. J.A Adegboyega. A.O Awosusi. Knowledge and the preventive strategies of malaria among migrant farmers in Ado Ekiti Local Government Area of Ekiti State, Nigeria. American Journal of Scientific and Industrial Research. 2(6) (2011) 883-889. https://doi.org/10.5251/ajsir.2011.2.6.883.889

[2] D.R Mohan, and M. Ramaswamy, Evaluation of larvicidal activity of the leaf extract of a weed plant, Ageratinaadenophora, against two important species of mosquitoes, Aedesaegyptiand Culexquinqefasciatus. African Journal of Biotechnology6 (2007) 631-638.

[3] Lucas and Giles Malaria: short textbook on public health and medicine for the tropics india, Arnold Publication. (2003).

[4] I.O Oyewole and A.C Ibidapo Attitude to malaria prevention, treatment and management strategies associated with prevalence of malaria in a Nigerian urban centre. Africa Journal of Biotechnology6 (21) (2007) 2424-2427. https://doi.org/10.5897/AJB2007.0002381 .

[5] J.S Khan., M.Usman, Y. Abbass. M Hussain, M. Alli, Knowledge,Attitude and Practise study on malaria. Gomal Journal of Medical Sciences8 (2) (2010) 204-208.

[6] Irin. Killer Number one: the fight against malaria Humanitarian News and Analysis. www.irinnews.org/indepthmain,aspx?indepththld (Retrieved May $8,2011)$.

[7] WHO (2002): WHO Expert committee on malaria twentieth Report. Geneva.

[8] S.C Uzochukwu, L.O Chiegboka, C. Enwereuzo, U.Nwosu, et al.,Examing appropriate diagnosis and treatment of malaria:availability and use of rapid diagnostics tests and arteminisinbaased combination therapy in public and private health facilities in south east, Nigeria.BioMed Central Public Health.https://doi.org/10.1186/1471(2010)-2458-10-486.

[9] O. Erenstein. B.Trederic, S.O.AkandeO.O.OgundeleThe Nigerian Rice Economy in a competitive world; Constraints, Opportunities and strategic choices; Rice production systems in Nigeria. A survey. A paper presented at the West Africa Rice development Association (WARDA) Abidjan, cote. (2003).

[10] D.W Batega. Knowledge, attitude and practise about malaria treatment and prevention in Uganda. A literature review final report pdf USAID.Gov/pdf. 2004.

[11] R.S Sharma, G.K. Sharma, G.P.S. Dhillion Epidemiology and control of malaria in India.Ministry of Health and Family Welfare NMEP (Directorate General of Health services) 1996.

[12] S. Sach.and P. Melaney. The economic and social burden of malaria.insight review articles centre for international development, John F.Kennedy School of Government,Havard University. (2010). 